\title{
Prevalence of venous obstructions in (recurrent) venous thromboembolism: a case-control study
}

Pascale Notten ${ }^{1,2+}$ (D), Rob H. W. Strijkers ${ }^{3+}$, Irwin Toonder ${ }^{3}$, Hugo ten Cate ${ }^{2,3,4}$ and Arina J. ten Cate-Hoek $2,3,4,5^{*}$

\begin{abstract}
Background: The role of venous obstructions as a risk factor for recurrent venous thromboembolism has never been evaluated. This study aimed to determine whether there is a difference in prevalence of venous obstructions between patients with and without recurrent venous thromboembolism. Furthermore, its influence on the development of post-thrombotic syndrome and patient-reported quality of life was assessed.

Methods: This matched nested case-control study included 32 patients with recurrent venous thromboembolism (26 recurrent deep-vein thrombosis and 6 pulmonary embolism) from an existing prospective cohort of deep-vein thrombosis patients and compared them to 24 age and sex matched deep-vein thrombosis patients without recurrent venous thromboembolism. All participants received standard post-thrombotic management and underwent an additional extensive duplex ultrasonography. Post-thrombotic syndrome was assessed by the Villaltascale and quality of life was measured using the SF36V2 and VEINES-QOL/Sym-questionnaires.

Results: Venous obstruction was found in 6 patients (18.8\%) with recurrent venous thromboembolism compared to 5 patients (20.8\%) without recurrent venous thromboembolism (Odds ratio $0.88,95 \% \mathrm{Cl} 0.23-3.30, p=1.000$ ). After a median follow-up of 60.0 months (IQR 41.3-103.5) the mean Villalta-score was $5.55 \pm 3.02$ versus $5.26 \pm 2.63$ ( $p=$ 0.909 ) and post-thrombotic syndrome developed in 20 (62.5\%) versus 14 (58.3\%) patients, respectively (Odds ratio $1.19,95 \% \mathrm{Cl} 0.40-3.51, p=0.752$ ). If venous obstruction was present, it was mainly located in the common iliac vein $(n=7,63.6 \%)$. In patients with an objectified venous obstruction the mean Villalta-score was $5.11 \pm 2.80$ versus $5.49 \pm 2.87$ in patients without venous obstruction $(p=0.639)$. Post-thrombotic syndrome developed in $6(54.5 \%)$ versus 28 (62.2\%) patients, respectively (Odds ratio 1.37, 95\%Cl 0.36-5.20, $p=0.736$ ). No significant differences were seen regarding patient-reported quality of life between either groups.

(Continued on next page)
\end{abstract}

\footnotetext{
* Correspondence: arina.tencate@maastrichtuniversity.nl

† Pascale Notten and Rob H. W. Strijkers contributed equally to this work.

${ }^{2}$ CARIM, Cardiovascular Research Institute Maastricht, School for

Cardiovascular Diseases, Maastricht University Medical Centre, P.O. Box 616,

Maastricht 6200 MD, the Netherlands

${ }^{3}$ Laboratory for Clinical Thrombosis and Hemostasis, Maastricht University,

P.O. Box 616, Maastricht 6200 MD, The Netherlands

Full list of author information is available at the end of the article
}

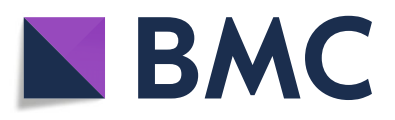

(c) The Author(s). 2020 Open Access This article is licensed under a Creative Commons Attribution 4.0 International License, which permits use, sharing, adaptation, distribution and reproduction in any medium or format, as long as you give appropriate credit to the original author(s) and the source, provide a link to the Creative Commons licence, and indicate if changes were made. The images or other third party material in this article are included in the article's Creative Commons licence, unless indicated otherwise in a credit line to the material. If material is not included in the article's Creative Commons licence and your intended use is not permitted by statutory regulation or exceeds the permitted use, you will need to obtain permission directly from the copyright holder. To view a copy of this licence, visit http://creativecommons.org/licenses/by/4.0/. The Creative Commons Public Domain Dedication waiver (http://creativecommons.org/publicdomain/zero/1.0/) applies to the data made available in this article, unless otherwise stated in a credit line to the data. 
(Continued from previous page)

Conclusions: In this exploratory case-control study patients with recurrent venous thromboembolism did not have a higher prevalence of venous obstruction compared to patients without recurrent venous thromboembolism. The presence of recurrent venous thromboembolism or venous obstruction had no impact on the development of post-thrombotic syndrome or the patient-reported quality of life.

Keywords: Venous thromboembolism, Deep vein thrombosis, Recurrence, Postthrombotic syndrome, Quality of life

\section{Background}

Following the acute phase, a substantial number of deep-vein thrombosis (DVT) patients face long-term post-thrombotic consequences. Despite optimal conservative treatment comprising of anticoagulation therapy, early mobilisation, and the use of therapeutic compression stockings, a recurrent venous thromboembolism (reVTE) will occur in about one-third of the patients within 10 years following a first DVT [1,2] with even higher risks in case of an unprovoked event [3, 4].

Subsequently, there is an increased risk of postthrombotic syndrome (PTS) [5]. PTS is a chronic condition characterised by a painful, swollen limb with paraesthesia, skin changes, venous claudication, and ultimately venous ulceration. It develops in 20$50 \%$ of all DVT patients [6-8] and is associated with a negative impact on the quality of life (QoL) [9] and increased health care costs [10].

According to Virchow's triad a disturbed or turbulent blood flow is one of the factors increasing the risk of thrombus formation. Obstruction of the venous tract, which can either be due to an anatomical anomality, or an intraluminal or extraluminal obstruction [11], induces impairment of the venous outflow [12]. This may lead to an increased risk of thrombosis due to stasis. However, it remains unknown if the presence of pre-existent venous obstruction (VO, meaning the presence of central venous obstructions and/or additional anatomic anomalies) is increased in patients with reVTE compared to patients without recurrence.

Since visualisation of the venous tract in the lower abdomen and pelvis with assessment of the inferior caval vein (ICV), common iliac vein (CIV), external iliac vein (EIV), and common femoral vein (CFV) is not incorporated into the standard diagnostic work-up for DVT, detection of VO through additional imaging is usually limited to patients presenting with more severe symptomatology in the acute phase and clinically suspect of having an iliofemoral DVT. Consequently, little is known regarding the presence of $\mathrm{VO}$ in relation to reVTE.

The risk of reVTE in case of venous outflow obstructions may be lowered by using (long-term) anticoagulant therapy. Additionally, new treatment modalities such as venous stenting make it possible to overcome (asymptomatic) central obstructions and restore venous flow
[13]. Therefore, if the presence of VO increases the risk for recurrent thrombosis, the preferred treatment strategy in these patients might switch from conservative into a more invasive treatment also influencing the duration of anticoagulant therapy.

This exploratory case-control study had the aim to assess the prevalence of VO in patients with reVTE (i.e. recurrent DVT or pulmonary embolism (PE)) compared to patients without reVTE. In addition, the association of reVTE and VO with PTS and the experienced QoL was analysed. The underlying hypothesis was that the presence of VO increases the risk of both reVTE and PTS and is associated with a reduced QoL as well.

\section{Methods}

\section{Study design}

This matched nested case-control study was based on a selection of patients from an existing prospective cohort of patients with a venous thromboembolism (VTE) who received treatment according to international guidelines at the department of Internal Medicine in the Maastricht University Medical Centre, the Netherlands [14]. All patients with a firsttime DVT of the femoropopliteal tract or more cranial vein segments were eligible for participation. Because the assessment for the diagnosis in the acute phase was not based on an extended duplex ultrasonography (DUS), the more cranial vein segments were not routinely identified/specified in the cohort database. Patients were excluded if they were younger than 18 years of age, pregnant, known to have an active malignancy, or if the patient refused unexpected medical findings to be communicated to the patient as well as to their general practitioner. Patients who had experienced a reVTE during follow-up were invited to participate in the current study by mail. When willing, they were requested to return a signed informed consent. Subsequently, an equal number of patients without reVTE (controls) who were matched by age and sex, were selected and approached. Informed consent had to be obtained before participation.

This study has been approved by the Medical Ethical Committee of the Maastricht University Medical Centre. All authors had full access to all the data in this study. 


\section{Clinical assessment}

All participants were invited for a single study visit at the outpatient clinic during which study assessments were performed. All study visits and assessments were performed by the same physician (RS) and registered vascular technologist (IT).

\section{Data collection}

A standardised case record form was used to gather all study data. This form included demographics, patient characteristics, disease-specific details (dates of primary and recurrent VTEs, provoked or unprovoked cause, risk factors), current post-thrombotic treatment (use of anticoagulant therapy, type of anticoagulant therapy, duration of treatment, adherence to compression therapy), clinical scores (Villalta-scale [15]) as well as results of an extended duplex ultrasonography assessment (presence of trabeculations or compression per vein segment, reflux, anatomic anomalies, and collaterals) of the affected leg.

\section{Patient characteristics}

The cohort database ascertained by medical records were used to obtain patient characteristics such as demographics, medical history concerning VTE, and details on the reVTE. Risk factors considered to be associated with reVTE were recent surgery, trauma or immobilization, long-term travelling, inflammation, the use of oral contraceptives, pregnancy and puerperium, obesity, a family history of VTE, and thrombophilia (factor $\mathrm{V}$ Leiden, antithrombin deficiency, prothrombin mutation, protein $\mathrm{C}$ deficiency, protein $\mathrm{S}$ deficiency, persistently elevated factor VIII, and/or antiphospholipid antibodies). The current use of anticoagulant medication and compression therapy as well as current risk enhancing factors for reVTE were assessed during the study visit.

\section{Duplex}

A standardised extended DUS was performed by one dedicated registered venous technologist (IT) assessing the inferior caval vein (ICV), common iliac vein (CIV), external iliac vein (EIV), common femoral vein (CFV), femoral vein (FV), deep femoral vein (DFV), and popliteal vein (PV) of the affected $\operatorname{leg}(\mathrm{s})$ in supine position. Venous outflow obstruction through the presence of anatomical anomalies, intraluminal post-thrombotic trabeculations and/or extraluminal compression was recorded for each vein segment separately. Reflux of the CFV and PV was assessed in upright position and based on a prolonged retrograde flow [16]. All DUS assessments were performed using an Esaote Spa ${ }^{\circ} 2019$ type MyLabAlpha with a broadband $1-8 \mathrm{MHz}$ curved array probe (AC2541).
Post-thrombotic morbidity and quality of life

The Villalta-scale [15] was recorded to assess postthrombotic morbidity at the time of the study visit. PTS was diagnosed according to the definition by the International Society on Thrombosis and Haemostasis (ISTH) which requires a single Villalta-score of 5 or higher or the presence of a venous ulcer obtained at 6 months or more after the initial thrombotic event [17]. PTS severity was categorised into none (Villalta score 0-4), mild (5$9)$, moderate (10-14), or severe ( $\geq 15$ or the presence of a venous ulcer). Patient reported quality of life was assessed using the generic SF36v2 [18] and diseasespecific VEINES QOL/Sym [19-21] questionnaires.

\section{Study outcomes}

The primary study outcome was the prevalence of $\mathrm{VO}$ in patients with reVTE compared to patients who had not developed reVTE. Secondary study outcomes regarded duplex findings, the development of PTS, and patient-reported QoL.

A reVTE comprised a recurrent DVT (reDVT) in the legs and/or PE. ReDVT was defined as an objectified DVT of the limb involving a new venous segment or a previously involved venous segment for which earlier symptomatic and imaging improvement had been obtained in a patient with at least one prior episode of DVT [22]. Results of imaging assessments were to be compared with previous assessments and reDVT was diagnosed in case of a) a new non-compressible, previously unaffected, or normalized vein segment (popliteal, femoral, iliac, or caval), b) extension of the thrombus margin, or c) an increased thrombus size [23-25]. PE was defined as the presence of complete or partial occlusion of the lung arteries in CT-pulmonary angiogram [22]. VO was defined as presence of either extraluminal compression of the CFV and/or more cranial vein segments (e.g. due to May Thurner Syndrome, adjacent anatomical structures, or a tumour), or any anatomical anomalies (e.g. agenesis, hypoplasia, aneurysms, anatomical variances and duplicates). In this study, post-thrombotic sequelae were registered separately and were defined as the presence of intraluminal trabeculations and/or synechiae.

\section{Statistical analysis}

Analyses were performed for the primary and secondary study outcomes by comparing the group of patients with reVTE versus those without reVTE. The study was matched on age and sex; stratified analyses on these matching factors was performed. In addition, subgroup analyses were performed for the baseline characteristics as well as secondary outcomes using the comparisons: provoked versus unprovoked VTE and VO versus no VO. Descriptive statistics were performed on patient 
characteristics and study outcomes using Student t-tests or Mann-Whitney U-tests for continuous variables and the Chi-squared or Fisher Exact test for categorical variables. Continuous data was presented as mean \pm standard deviation, categorical data was presented with absolute number and percentages or Odds ratio (OR) and their associated 95\% confidence interval $(95 \% \mathrm{CI})$. The Jonckheere-Terpstra test was performed on the Villalta scores (total score, subjective score, and objective score) for trends. A significance level of 0.05 (two-sided) or less was considered statistically significant. All analyses were performed using SPSS, version 24.

\section{Results}

\section{Patient characteristics}

Forty patients with reVTE that were alive and whose contact data were available were identified from the cohort database of DVT patients treated at the outpatient clinic of the Maastricht University Medical Centre [14]. Twenty-nine patients responded to our invitation to participate in this exploratory casecontrol study and signed the informed consent form.
These 29 patients were then age and sex matched to 29 controls who had not experienced reVTE according to the data available in the database. Therefore, in total 58 patients signed informed consent and were included in the study. Information obtained during data ascertainment of the patients' medical records and at the study visit showed that in two out of the 29 patients the recurrent event concerned an upper extremity thrombosis. Furthermore, five of the 29 matched controls for whom no reVTE was recorded in the database actually had experienced a reVTE. Hence the final study sample includes $56 \mathrm{pa}-$ tients of which 32 patients with reVTE (26 reDVT and $6 \mathrm{PE}$ ) and 24 patients who had not experienced a recurrent event (Table 1). Patients had a median age of 67.0 (Inter Quartile Range 57.0-71.0) years and were predominantly male (82.1\%). An unprovoked cause of the first DVT was significantly more common in patients with reVTE: 23 out of 32 patients $(71.9 \%)$ versus ten out of 24 patients $(41.7 \%)$, $(P=0.03)$. In seven patients (six $(18.8 \%)$ versus one $(4.2 \%) ; p=0.219)$ thrombophilia was known; the prevalence of elevated factor VIII (defined as $>213 \%$

Table 1 Baseline characteristics

\begin{tabular}{|c|c|c|c|}
\hline & $\begin{array}{l}\text { Recurrent VTE } \\
N=32\end{array}$ & $\begin{array}{l}\text { No recurrent VTE } \\
N=24\end{array}$ & $P$-value \\
\hline Age, years & $68.0(61.3-72.0)$ & $65.0(45.3-70.8)$ & 0.223 \\
\hline Sex & & & 0.298 \\
\hline - Male & $28(87.5)$ & $18(75.0)$ & 0.298 \\
\hline - Female & $4(12.5)$ & $6(25.0)$ & 0.298 \\
\hline Unprovoked DVT & $23(71.9)$ & $10(41.7)$ & 0.030 \\
\hline Affected side initial event & & & 0.697 \\
\hline - Left & $13(40.6)$ & $11(45.8)$ & 0.697 \\
\hline - Right & 19 (59.4) & $13(54.2)$ & 0.697 \\
\hline \multicolumn{4}{|l|}{ Affected side recurrent event } \\
\hline - Ipsilateral ( \pm pulmonary embolism) & $17(53.1)$ & $\mathrm{n} / \mathrm{a}$ & - \\
\hline - Contralateral ( \pm pulmonary embolism) & $9(28.1)$ & $\mathrm{n} / \mathrm{a}$ & - \\
\hline - Pulmonary embolism & $6(18.8)$ & $\mathrm{n} / \mathrm{a}$ & - \\
\hline History of pulmonary embolism & $8(25.0)^{a}$ & $4(16.7)^{b}$ & 0.525 \\
\hline Family history of DVT & $10(31.3)$ & $3(12.5)$ & 0.122 \\
\hline Antithrombotic therapy & $32(100.0)$ & $17(70.8)$ & 0.001 \\
\hline Antithrombotic therapy, type & & & 0.071 \\
\hline - VKA & $26(81.3 \%)$ & $16(66.7)$ & 0.212 \\
\hline$-D O A C^{C}$ & $6(18.8 \%)$ & $0(0.0)$ & 0.035 \\
\hline Elastic compression stockings, use & $19(59.4)$ & $3(12.5)$ & $<0.001$ \\
\hline
\end{tabular}

Data are $\mathrm{n}(\%)$ or median (IQR)

DOAC Direct oral anticoagulant, DVT Deep venous thrombosis, LMWH Low Molecular Weight Heparin, n/a Not applicable, VKA Vitamin K Antagonist, VTE Venous Thrombo-Embolism

${ }^{a}$ All pulmonary embolisms were recurrent VTE which developed after the primary thrombo-embolic event. In 6 patients it presented as a solitary pulmonary

embolism and in 2 patients it presented concurrent with a recurrent deep-vein thrombosis

${ }^{\mathrm{b}}$ All pulmonary embolism were concurrent with the primary thrombo-embolic event

c The DOACs used were Rivaroxaban $(n=4)$, Apixaban $(n=1)$, and Dabigatran $(n=1)$ 
[14]) was significantly higher in patients with reVTE ( $\operatorname{six}(18.8 \%)$ versus none $(0.0 \%) ; p=0.035)$.

The current use of anticoagulant therapy and compression therapy was significantly higher in the reVTEgroup: $100 \%$ (32 out of 32) versus $70.8 \%$ (17 out of 24 ), $p=0.001$, and $59.4 \%$ (19 out of 32 ) versus $12.5 \%$ (three out of 24), $p<0.001$, respectively. Most commonly used were the VKA: 26 out of $32(81.3 \%)$ in patients with reVTE versus 16 (66.7\%) out of 24 controls. A significant difference in the use of direct oral anticoagulants was seen, being restricted to patients with reVTE: six out of $32(18.8 \%)$ versus none of the controls $(0.0 \%), p=0.035)$. Indication for indefinite treatment duration was more frequent in patients with reVTE: 30 out of 32 (93.8\%) versus six out of 24 (25.0\%), $p<0.001$.

\section{Study outcomes}

There was no significant difference in the prevalence of VO between groups: six (18.8\%) in patients who had experienced a recurrent event versus five (20.8\%) in patients who did not; OR 0.88 (95\%CI $0.23-3.30$ ), $p=1.000$ (Table 2). The presence of abnormalities on duplex findings such as extraluminal compression (four (12.5\%) versus three (12.5\%), OR 1.00 (95\%CI $0.20-4.96), \quad p=1.000)$, intraluminal post-thrombotic sequelae $(28(87.5 \%)$ versus 18 (75.0\%), OR 2.33 (95\%CI $0.58-9.43), p=0.298)$, or venous insufficiency (19 (59.4\%) versus 10 (41.7\%), OR 2.05 (95\%CI $0.70-$ $6.00), p=0.189$ ) did not differ either (Table 3).

Compression was seen solely in the caval and iliac tract: the ICVir (one (3.1\%) versus two (8.3\%) respectively, $p=1.000$ ), the CIV (four (12.5\%) versus three (12.5\%), $p=1.000$ ), and EIV (one (3.1\%) versus none
(0.0\%), $p=0.126)$. Trabeculations were most commonly seen in the popliteal (27 (79.4\%) versus $16(66.7 \%), p=$ $0.200)$ and femoral vein $(18(56.3 \%)$ versus $9(37.5 \%)$, $p=0.165)$. In only two $(6.3 \%)$ versus five $(20.8 \%)$ patients all vein segments were free of anomalies $(p=$ 0.642). There was no difference for any of the results whether the right or left leg was affected.

The mean Villalta score was $5.55 \pm 3.02$ in patients with reVTE compared to $5.26 \pm 2.63$ in patients without reVTE $(p=0.909)$, composed of objective (4.03 \pm 3.07 versus $3.08 \pm$ $1.74, p=0.519)$ and subjective $(1.63 \pm 1.43$ versus $2.22 \pm$ 2.30, $p=0.512$ ) components. No significant trends were seen in the mean total $(p=0.909)$, objective $(p=0.519)$, or subjective $(p=0.512)$ Villalta-score. PTS and PTS severity was similar between groups. There were no differences in the reported QoL according to the SF36v2, overall score $(p=0.493)$ as well as the scores per individual category (all $P>0.156)$, and the VEINES-QOL/Sym $(p=0.518$ for the total score and $p=0.966$ for the intrinsic score) (Table 4).

Furthermore, analyses regarding outcomes of the DUS assessment and the clinical assessments for the Villalta-score, PTS, PTS severity, and QoL were also performed for two subgroups: patients with or without an unprovoked cause for the primary DVT and patients with and without VO.

These analyses showed that patients with an unprovoked cause of the primary DVT $(n=33,58.9 \%)$ did not differ from patients with a provoked primary event nor were there differences in outcomes.

VO was found in $11(19.6 \%)$ of the 56 patients of which seven (12.5\%) included extraluminal caval or iliac compression. Patients with VO were significantly younger than patients without VO (61.0 (IQR 32.0-69.0) versus 68.0 (IQR 59.5-72.0), $p=0.046$ ). Apart from age there were no other

Table 2 Details in patients with central venous obstructions and anatomic anomalies

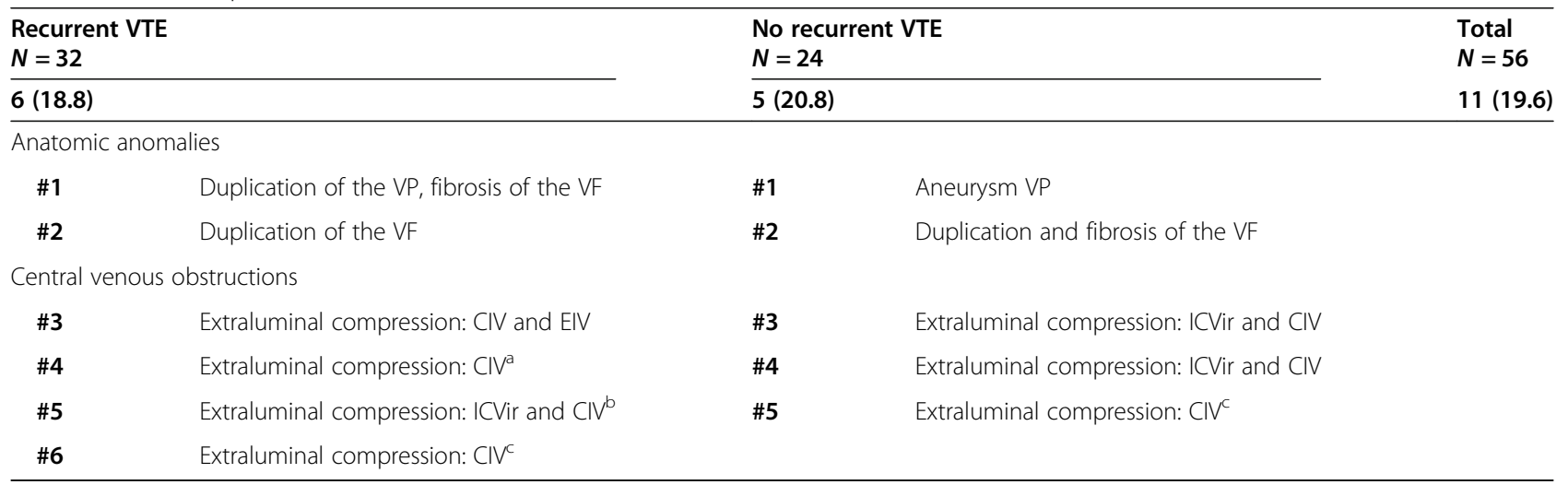

Data are $\mathrm{n}(\%)$

ICVir Inferior caval vein, infra renal, CIV Common iliac vein, EIV External iliac vein, FV Femoral vein, PV Popliteal vein, VTE Venous thrombo-embolism None of the variables mentioned in this table showed statistical significant difference between groups

Venous obstruction is defined as either extraluminal compression (e.g. due to May-Thurner Syndrome, adjacent anatomical structures, pelvic tumour) or the presence of anatomical anomalies (e.g. agenesis, hypoplasia, aneurysms, anatomical variances, and duplications) that might negatively influence the central venous flow

${ }^{a}$ Extraluminal compression caused by spondylosis

${ }^{\mathrm{b}}$ Extraluminal compression caused by the left iliac artery

c Extraluminal compression caused by May Thurner Syndrome (compression by the right iliac artery) 
Table 3 Results duplex assessment ${ }^{\mathrm{a}}$

\begin{tabular}{|c|c|c|c|c|}
\hline & $\begin{array}{l}\text { Recurrent VTE } \\
N=32\end{array}$ & $\begin{array}{l}\text { No recurrent VTE } \\
N=24\end{array}$ & $\begin{array}{l}\text { Total } \\
N=56\end{array}$ & Odds ratio $(95 \% \mathrm{Cl})$ \\
\hline Extraluminal compression & $4(12.5)$ & $3(12.5)$ & $7(12.5)$ & $1.00(0.20-4.96)$ \\
\hline \multicolumn{5}{|c|}{ Extraluminal compression, per vein segment } \\
\hline ICVir & $1(3.1)$ & $2(8.3)$ & $3(5.6)$ & $0.36(0.03-1.16)$ \\
\hline CIV & $4(12.5)$ & $3(12.5)$ & $7(12.5)$ & $1.00(0.20-4.96)$ \\
\hline EIV & $1(3.1)$ & $0(0.0)$ & $1(1.8)$ & $2.33(0.09-59.8)$ \\
\hline Post-thrombotic sequalae ${ }^{b}$ & $28(87.5)$ & $18(75.0)$ & $46(82.1)$ & $2.33(0.58-9.43)$ \\
\hline \multicolumn{5}{|c|}{ Trabeculations, per vein segment } \\
\hline ICVsr & $1(3.1)$ & $0(0.0)$ & $1(1.8)$ & $2.33(0.09-59.8)$ \\
\hline ICVir & $1(3.1)$ & $1(4.2)$ & $2(3.6)$ & $0.74(0.04-12.5)$ \\
\hline CIV & $2(6.3)$ & $3(12.5)$ & $5(8.9)$ & $0.47(0.07-3.04)$ \\
\hline EIV & $3(9.4)$ & $3(12.5)$ & $6(10.7)$ & $0.72(0.13-3.95)$ \\
\hline CFV & $3(9.4)$ & $4(16.7)$ & $7(12.5)$ & $0.52(0.10-2.57)$ \\
\hline FV & $18(56.3)$ & $9(37.5)$ & $27(48.2)$ & $2.14(0.73-6.32)$ \\
\hline DFV & $1(3.1)$ & $1(4.2)$ & $2(3.6)$ & $0.74(0.04-12.5)$ \\
\hline PV & $27(79.4)$ & $16(66.7)$ & $43(76.8)$ & $2.70(0.75-9.68)$ \\
\hline Venous insufficiency ${ }^{c}$ & $19(59.4)$ & $10(41.7)$ & $29(51.8)$ & $2.05(0.70-6.00)$ \\
\hline \multicolumn{5}{|c|}{ Venous insufficiency, per vein segment } \\
\hline CFV & $3(9.4)$ & $0(0.0)$ & $3(5.6)$ & $5.81(0.29-118.1)$ \\
\hline PV & $19(59.4)$ & $10(41.7)$ & $29(51.8)$ & $2.05(0.70-6.00)$ \\
\hline
\end{tabular}

Data are $\mathrm{n}(\%)$

None of the variables mentioned in this table showed statistical significant difference between groups

ICVsr Inferior caval vein, supra renal, ICVir Inferior caval vein, infra renal, CIV Common iliac vein, EIV External iliac vein, CFV Common femoral vein, FV Femoral vein, DFV Deep femoral vein, PV Popliteal vein, VTE Venous thrombo-embolism

${ }^{a}$ During the standardized duplex ultrasound study assessment the presence of extraluminal compression and/or trabeculations was assessed per individual vein segment of the affected leg(s) being the ICVsr, ICVir, CIV, EIV, CFV, FV, DFV, and PV. Venous insufficiency was assessed in the CFV and PV

${ }^{b}$ Post-thrombotic sequelae are defined as the presence of intraluminal trabeculations or synechiae

'Venous insufficiency was defined as a retrograde flow longer than $1 \mathrm{~s}$ [16]

differences between these groups. Based on the definition used, compression was seen only in the patients with VO: seven $(63.6 \%)$ versus none $(0.0 \%)$, OR 0.01 (95\%CI 0.00 $0.14), p<0.001$. No differences were seen regarding intraluminal post-thrombotic trabeculations (nine $(81.8 \%)$ versus 37 (82.2\%), OR 1.03 (95\%CI 0.19-5.70), $p=1.000$ ) or venous insufficiency (six (54.5\%) versus 23 (51.1\%), OR 0.87 (95\%CI $0.23-3.27$ ), $p=1.000$ ). The Villalta scores did not differ between groups (Total Villalta: $5.11 \pm 2.80$ versus $5.49 \pm 2.87, p=0.639$; objective Villalta: $4.00 \pm 3.02$ versus $3.53 \pm 2.53, p=0.748$; and subjective Villalta score: $1.50 \pm$ 1.51 versus $1.96 \pm 1.92, p=0.546$. Results regarding PTS, PTS severity, and QoL were also comparable between patients with and without VO.

\section{Discussion}

In this exploratory case-control study we did not find a difference in prevalence of $\mathrm{VO}$ between patients that did and patients that did not develop a recurrent thrombotic event. Moreover, no impact of the absence of either reVTE or VO was seen regarding the development of PTS or on the experienced QoL.
Also, the sub analysis comparing patients with $\mathrm{VO}$ to patients without VO showed no differences in postthrombotic trabeculations or venous insufficiency on DUS assessment. This may indicate that there is no association between the presence of $\mathrm{VO}$ and long-term post-thrombotic intraluminal sequelae. No differences were seen for the prevalence of PTS, the severity of PTS, and QoL. However, we did find that patients with VO were younger than patients without $\mathrm{VO}$, suggesting that these patients might be at risk for VTE development at an earlier age. This would be in line with the expected initial increased risk of thrombus formation under conditions of disturbed or turbulent blood flow.

However, our results do not indicate that VO increases the risk of developing reVTE. Furthermore, the presence of $\mathrm{VO}$ does not result in a worse clinical outcome regarding PTS and QoL in patients with recurrence. Therefore, one needs to critically consider whether DVT patients with objectified $\mathrm{VO}$ or patients with asymptomatic VO will benefit from prolonged anticoagulant therapy or more invasive treatments such as venous stenting. 
Table 4 Long-term treatment outcomes

\begin{tabular}{|c|c|c|c|c|}
\hline & $\begin{array}{l}\text { Recurrent VTE } \\
N=32\end{array}$ & $\begin{array}{l}\text { No recurrent VTE } \\
N=24\end{array}$ & $\begin{array}{l}\text { Total } \\
N=56\end{array}$ & Odds ratio $(95 \% \mathrm{Cl})$ \\
\hline Villalta score [15] & $5.55 \pm 3.02$ & $5.26 \pm 2.63$ & $5.43 \pm 2.84$ & - \\
\hline - Subjective score & $1.63 \pm 1.43$ & $2.22 \pm 2.30$ & $1.87 \pm 1.85$ & - \\
\hline - Objective score & $4.03 \pm 3.07$ & $3.08 \pm 1.74$ & $3.62 \pm 2.60$ & - \\
\hline Post-Thrombotic syndrome ${ }^{a}[15,17]$ & $20(62.5)$ & $14(58.3)$ & $34(60.7)$ & $1.19(0.40-3.51)$ \\
\hline - None (0-4) & $11(34.4)$ & $9(37.5)$ & $20(35.7)$ & $0.87(0.29-2.63)$ \\
\hline - Mild (5-9) & $17(53.1)$ & $11(45.8)$ & $28(50.0)$ & $1.34(0.46-3.87)$ \\
\hline - Moderate (10-14) & $3(9.4)$ & $3(12.5)$ & $6(10.7)$ & $0.72(0.13-3.95)$ \\
\hline - Severe ( $\geq 15$ or venous ulceration) & $0(0.0)$ & $0(0.0)$ & $0(0.0)$ & $0.75(0.01-39.3)$ \\
\hline - Missing & $1(3.1)$ & $1(4.2)$ & $2(3.6)$ & $0.74(0.04-12.5)$ \\
\hline SF- $36^{\mathrm{b}}$ - Reported health transition & $51.7 \pm 18.5$ & $52.1 \pm 14.6$ & $51.9 \pm 16.7$ & - \\
\hline VEINES QOL/Symc & $49.5 \pm 11.1$ & $51.5 \pm 8.2$ & $50.4 \pm 9.9$ & - \\
\hline VEINES QOL/Sym, intrinsic score ${ }^{d}$ & $71.3 \pm 14.8$ & $72.4 \pm 12.2$ & $71.8 \pm 13.6$ & - \\
\hline
\end{tabular}

Data are $\mathrm{n}(\%)$ or mean $\pm \mathrm{SD}$

None of the variables mentioned in this table showed statistical significant difference between groups

VTE Venous thrombo-embolism

a Post-thrombotic syndrome was defined according to the definition stated by the International Society of Thrombosis and Haemostasis. This definition requires a single Villalta-score $\geq 5$ assessed at 6 months or more after the acute venous thrombo-embolic event [17]

${ }^{\mathrm{b}}$ The SF-36 is a questionnaire aimed at the generic health-related quality of life as reported by the patients. It comprises 36 questions covering 8 different healthrelated dimensions: Physical functioning, Role limitations due to physical health, Role limitations due to emotional health, Energy/Fatigue, Emotional well-being, Social functioning, Bodily pain, and General health perceptions [18]

'The VEINES QOL/SYM is a questionnaire addressing the disease-specific self-reported quality of life in DVT patients. It entails 25 questions regarding the limitations, symptoms, and changes encountered as a result of the acute thromboembolic event. The final summarizing score is adapted to the study population $[19,20]$

${ }^{\mathrm{d}}$ By using the method by Bland et al. [21] the VEINES QOL/SYM summarizing score can be transformed into an intrinsic score which allows comparison to other quality of life scores

This study has several limitations. First of all, the number of included patients was low, this may especially affect the results of the sub analyses between patients with an unprovoked versus provoked VTE and between patients with and without VO. However, although it is an exploratory study and as such unable to be conclusive, its results can be used in the discussion regarding the need for long-term anticoagulation or indications for venous stenting. We found that $\mathrm{VO}$ is equally prevalent in patients with or without reVTE and as such VO is not a likely game changer for recurrent risk.

Second, the characteristics of the patients included in this study may differ from those in other post-thrombotic populations and therefore our findings might not be generalisable. Remarkable, yet without difference between the groups studied, was the high percentage of male patients $(82.1 \%)$ and thrombosis with a right-sided (57.1\%) thrombus localisation [5, 26, 27]. Also the incidence of PTS was high (60.7\%) compared to the general post-thrombotic population [6-8] and was mainly based on high objective scores.

In addition, patients with reVTE differed from their age and sex matched controls regarding several baseline characteristics known to have a role in the pathophysiology of DVT and its post-thrombotic morbidity [5, 7, 8, 28-42]. This might have influenced the clinical outcomes. For example, the higher use of compression stockings in patients with a reVTE may have limited the development of PTS and post-thrombotic signs or symptoms [33, 34]. The reason for a difference in compliance to compression therapy could not be determined based on the available data. Since all patients were treated according to international guidelines for post-thrombotic care, by definition the anticoagulant management following a reVTE differed from management following a single episode.

Nevertheless, since the influence of $\mathrm{VO}$ on the occurrence of reVTE had not been studied before, our study provides, to our knowledge, the first insight in the characteristics of patients with VO. Clearly defined inclusion criteria and selection from an existing cohort of patients that received standardized post-thrombotic care are some of the strengths of this study. Furthermore, all consultations and duplex assessments were performed by the same physician (RS) and a highly experienced registered vascular technologist (IT), respectively, who both had no involvement in the primary care process of these patients.

\section{Conclusions}

In conclusion, this exploratory study suggests that the presence of $\mathrm{VO}$ is not related to recurrent thrombotic events, nor to the clinical outcome following reVTE. Therefore, (asymptomatic) VO does not seem to provide a basis for specific treatment such as prolonged anticoagulant treatment or stenting, as means of reducing the risk of recurrent thrombosis. 


\section{Abbreviations}

CFV: Common femoral vein; CIV: Common iliac vein; DFV: Deep femoral vein; DUS: Duplex ultrasonography; DVT: Deep-vein thrombosis; EIV: External iliac vein; FV: Femoral vein; ICV: Inferior caval vein; ICVir: Inferior caval vein, infra renal; ICVsr: Inferior caval vein, supra renal; IQR: Interquartile range; ISTH: International Society on Thrombosis and Haemostasis; OR: Odds ratio; PE: Pulmonary embolism; PTS: Post-thrombotic syndrome; PV: Popliteal vein; QoL: Quality of life; reDVT: Recurrent DVT; reVTE: Recurrent venous thromboembolism; VO: Venous obstruction; VTE: Venous thromboembolism; 95\%Cl: 95\% confidence interval

\section{Acknowledgements}

Not applicable.

\section{Authors' contributions}

PN contributed to literature search, data collection, composition of the database, data analysis, data interpretation, composition of tables, and writing of the manuscript. RS and IT contributed to collection of the data and critical review of the manuscript. HtC contributed to study concept, study design, and critical review of the manuscript. AtCH conceived the study including protocol development, gaining ethical approval, and patient recruitment and contributed to data analysis, data interpretation, composition of tables, and writing of the manuscript. All authors read and approved the final manuscript.

\section{Funding}

Not applicable.

\section{Availability of data and materials}

The datasets generated and/or analysed during the current study are available from the corresponding author AJtC-H (arina.tencate@maastrichtuniversity.nl) on reasonable request.

\section{Ethics approval and consent to participate}

This study has been approved by the Medical Ethical Committee of the Maastricht University Medical Centre. Patients had to provide informed consent prior to participation.

\section{Consent for publication}

Not applicable.

\section{Competing interests}

RS received grants from AB Medica, Angiocare, Angiodynamics, Bayer, Boston Scientific Group, BTG, Cook Medical, Medtronic, and Optimed during the conduct of this study. The other authors declare that they have no competing interests.

\section{Author details}

${ }^{1}$ Department of Vascular Surgery, Maastricht University Medical Centre, P.O. Box 5800, Maastricht 6202 AZ, the Netherlands. ${ }^{2}$ CARIM, Cardiovascular Research Institute Maastricht, School for Cardiovascular Diseases, Maastricht University Medical Centre, P.O. Box 616, Maastricht 6200 MD, the Netherlands. ${ }^{3}$ Laboratory for Clinical Thrombosis and Hemostasis, Maastricht University, P.O. Box 616, Maastricht 6200 MD, The Netherlands. ${ }^{4}$ Thrombosis Expertise Centre, Heart + Vascular Centre, Maastricht University Medical Centre, P.O. Box 5800, Maastricht 6202 AZ, the Netherlands. ${ }^{5}$ Thrombosis Expertise Centre, Heart + Vascular Centre, Maastricht University Medical Centre, P. Debyelaan 25, Maastricht 6229 HX, the Netherlands.

Received: 15 May 2020 Accepted: 8 September 2020

Published online: 16 September 2020

\section{References}

1. Heit JA. Epidemiology of venous thromboembolism. Nat Rev Cardiol. 2015; 12(8):464-74.

2. Khan F, Rahman A, Carrier M, Kearon C, Weitz Jl, Schulman S, et al. Long term risk of symptomatic recurrent venous thromboembolism after discontinuation of anticoagulant treatment for first unprovoked venous thromboembolism event: systematic review and meta-analysis. BMJ. 2019;366:14363.

3. Prandoni P, Noventa F, Ghirarduzzi A, Pengo V, Bernardi E, Pesavento R, et al. The risk of recurrent venous thromboembolism after discontinuing anticoagulation in patients with acute proximal deep vein thrombosis or pulmonary embolism. A prospective cohort study in 1,626 patients. Haematologica. 2007;92(2):199-205.

4. Iorio A, Kearon C, Filippucci E, Marcucci M, Macura A, Pengo V, et al. Risk of recurrence after a first episode of symptomatic venous thromboembolism provoked by a transient risk factor: a systematic review. Arch Intern Med. 2010;170(19):1710-6.

5. Kahn SR, Comerota AJ, Cushman M, Evans NS, Ginsberg JS, Goldenberg NA, et al. The postthrombotic syndrome: evidence-based prevention, diagnosis, and treatment strategies: a scientific statement from the American Heart Association. Circulation. 2014:130(18):1636-61.

6. Prandoni $P$, Lensing AW, Prins MH, Pesavento $R$, Piccioli $A$, Sartori MT, et al. The impact of residual thrombosis on the long-term outcome of patients with deep venous thrombosis treated with conventional anticoagulation. Semin Thromb Hemost. 2015:41(2):133-40.

7. Kahn SR, Shrier I, Julian JA, Ducruet T, Arsenault L, Miron MJ, et al. Determinants and time course of the postthrombotic syndrome after acute deep venous thrombosis. Ann Intern Med. 2008;149(10):698-707.

8. Schulman $S$, Lindmarker $P$, Holmstrom M, Larfars G, Carlsson A, Nicol P, et al. Post-thrombotic syndrome, recurrence, and death 10 years after the first episode of venous thromboembolism treated with warfarin for 6 weeks or 6 months. J Thromb Haemost. 2006;4(4):734-42.

9. Kahn SR, Shbaklo H, Lamping DL, Holcroft CA, Shrier I, Miron MJ, et al. Determinants of health-related quality of life during the 2 years following deep vein thrombosis. J Thromb Haemost. 2008;6(7):1105-12.

10. Ten Cate-Hoek AJ, Toll DB, Buller HR, Hoes AW, Moons KG, Oudega R, et al. Cost-effectiveness of ruling out deep venous thrombosis in primary care versus care as usual. J Thromb Haemost. 2009;7(12):2042-9.

11. Meissner $M H$, Eklof $B$, Smith PC, Dalsing MC, DePalma RG, Gloviczki $P$, et al. Secondary chronic venous disorders. J Vasc Surg. 2007:46(Suppl S):68s-83s.

12. Neglen $P$, Thrasher TL, Raju S. Venous outflow obstruction: an underestimated contributor to chronic venous disease. J Vasc Surg. 2003;38(5):879-85.

13. Broholm R, Panduro Jensen L, Baekgaard N. Catheter-directed thrombolysis in the treatment of iliofemoral venous thrombosis. A review. Int Angiol. 2010;29(4):292-302.

14. Nagler M, Ten Cate $\mathrm{H}$, Prins $\mathrm{MH}$, Ten Cate-Hoek AJ. Risk factors for recurrence in deep vein thrombosis patients following a tailored anticoagulant treatment incorporating residual vein obstruction. Res Pract Thromb Haemost. 2018;2(2):299-309.

15. Villalta SB, Bagatella P, Piccioli A, Lensing A, Prins M, Prandoni P. Assessment of validity and reproducibility of a clinical scale for the post-thrombotic syndrome. Haemostasis. 1994;24(suppl 1):158a.

16. Wittens C, Davies AH, Baekgaard N, Broholm R, Cavezzi A, Chastanet S, et al. Editor's choice - management of chronic venous disease: clinical practice guidelines of the European Society for Vascular Surgery (ESVS). Eur J Vasc Endovasc Surg. 2015;49(6):678-737.

17. Kahn SR, Partsch H, Vedantham S, Prandoni P, Kearon C. Definition of postthrombotic syndrome of the leg for use in clinical investigations: a recommendation for standardization. J Thromb Haemost. 2009:7(5):879-83.

18. Aaronson NK, Muller M, Cohen PD, Essink-Bot ML, Fekkes M, Sanderman R, et al. Translation, validation, and norming of the Dutch language version of the SF-36 Health Survey in community and chronic disease populations. J Clin Epidemiol. 1998:51(11):1055-68.

19. van der Velden SK, Biemans AA, Nijsten T, Sommer A. Translation and validation of the Dutch VEINES-QOL/Sym in varicose vein patients. Phlebology. 2014;29(4):227-35.

20. Lamping DL, Schroter S, Kurz X, Kahn SR, Abenhaim L. Evaluation of outcomes in chronic venous disorders of the leg: development of a scientifically rigorous, patient-reported measure of symptoms and quality of life. J Vasc Surg. 2003;37(2):410-9.

21. Bland JM, Dumville JC, Ashby RL, Gabe R, Stubbs N, Adderley U, et al. Validation of the VEINES-QOL quality of life instrument in venous leg ulcers: repeatability and validity study embedded in a randomised clinical trial. BMC Cardiovasc Disord. 2015:15:85

22. Vedantham S, Thorpe PE, Cardella JF, Grassi CJ, Patel NH, Ferral H, et al. Quality improvement guidelines for the treatment of lower extremity deep vein thrombosis with use of endovascular thrombus removal. J Vasc Interv Radiol. 2009:20(7 Suppl):S227-39.

23. Linkins LA, Pasquale $P$, Paterson $S$, Kearon $C$. Change in thrombus length on venous ultrasound and recurrent deep vein thrombosis. Arch Intern Med. 2004;164(16):1793-6. 
24. Prandoni P, Lensing AW, Bernardi E, Villalta S, Bagatella P, Girolami A. The diagnostic value of compression ultrasonography in patients with suspected recurrent deep vein thrombosis. Thromb Haemost. 2002;88(3):402-6.

25. Prandoni $\mathrm{P}$, Cogo A, Bernardi E, Villalta S, Polistena P, Simioni P, et al. A simple ultrasound approach for detection of recurrent proximal-vein thrombosis. Circulation. 1993;88(4 Pt 1):1730-5.

26. Nordstrom M, Lindblad B, Bergqvist D, Kjellstrom T. A prospective study of the incidence of deep-vein thrombosis within a defined urban population. J Intern Med. 1992;232(2):155-60.

27. Johansson M, Johansson L, Lind M. Incidence of venous thromboembolism in northern Sweden (VEINS): a population-based study. Thromb J. 2014;12(1):6.

28. Bauersachs R, Berkowitz SD, Brenner B, Buller HR, Decousus H, Gallus AS, et al. Oral rivaroxaban for symptomatic venous thromboembolism. N Engl J Med. 2010;363(26):2499-510.

29. Tick LW, Kramer MH, Rosendaal FR, Faber WR, Doggen CJ. Risk factors for post-thrombotic syndrome in patients with a first deep venous thrombosis. J Thromb Haemost. 2008:6(12):2075-81.

30. Tick LW, Doggen CJ, Rosendaal FR, Faber WR, Bousema MT, Mackaay AJ, et al. Predictors of the post-thrombotic syndrome with non-invasive venous examinations in patients 6 weeks after a first episode of deep vein thrombosis. J Thromb Haemost. 2010;8(12):2685-92.

31. Stain M, Schonauer V, Minar E, Bialonczyk C, Hirschl M, Weltermann A, et al. The post-thrombotic syndrome: risk factors and impact on the course of thrombotic disease. J Thromb Haemost. 2005;3(12):2671-6.

32. Douketis JD, Crowther MA, Foster GA, Ginsberg JS. Does the location of thrombosis determine the risk of disease recurrence in patients with proximal deep vein thrombosis? Am J Med. 2001;110(7):515-9.

33. Ten Cate-Hoek AJ, Amin EE, Bouman AC, Meijer K, Tick LW, Middeldorp S, et al. Individualised versus standard duration of elastic compression therapy for prevention of post-thrombotic syndrome (IDEAL DVT): a multicentre, randomised, single-blind, allocation-concealed, non-inferiority trial. Lancet Haematol. 2018;5(1):e25-33.

34. Brandjes DP, Buller HR, Heijboer $\mathrm{H}$, Huisman MV, de Rijk M, Jagt $\mathrm{H}$, et al. Randomised trial of effect of compression stockings in patients with symptomatic proximal-vein thrombosis. Lancet. 1997;349(9054):759-62

35. Galanaud JP, Monreal M, Kahn SR. Epidemiology of the post-thrombotic syndrome. Thromb Res. 2018;164:100-9.

36. Labropoulos N, Jen J, Jen H, Gasparis AP, Tassiopoulos AK. Recurrent deep vein thrombosis: long-term incidence and natural history. Ann Surg. 2010;251(4):749-53.

37. Kearon C, Akl EA, Ornelas J, Blaivas A, Jimenez D, Bounameaux H, et al. Antithrombotic therapy for VTE disease: CHEST guideline and expert panel report. Chest. 2016;149(2):315-52.

38. Appelen D, van Loo E, Prins MH, Neumann MH, Kolbach DN. Compression therapy for prevention of post-thrombotic syndrome. Cochrane Database Syst Rev. 2017;9:Cd004174.

39. Ten Cate-Hoek AJ, Prins MH, Wittens $\mathrm{CH}$, ten Cate H. Postintervention duration of anticoagulation in venous surgery. Phlebology. 2013;28(Suppl 1):105-11.

40. Hull RD, Liang J, Townshend G. Long-term low-molecular-weight heparin and the post-thrombotic syndrome: a systematic review. Am J Med. 2011;124(8):756-65.

41. Schulman S, Kearon C, Kakkar AK, Mismetti P, Schellong S, Eriksson H, et al. Dabigatran versus warfarin in the treatment of acute venous thromboembolism. N Engl J Med. 2009;361(24):2342-52.

42. van Dongen CJ, Prandoni P, Frulla M, Marchiori A, Prins MH, Hutten BA. Relation between quality of anticoagulant treatment and the development of the postthrombotic syndrome. J Thromb Haemost. 2005;3(5):939-42.

\section{Publisher's Note}

Springer Nature remains neutral with regard to jurisdictional claims in published maps and institutional affiliations.

Ready to submit your research? Choose BMC and benefit from:
- fast, convenient online submission
- thorough peer review by experienced researchers in your field
- rapid publication on acceptance
- support for research data, including large and complex data types
- gold Open Access which fosters wider collaboration and increased citations
- maximum visibility for your research: over 100M website views per year
At BMC, research is always in progress.
Learn more biomedcentral.com/submissions

